\title{
Comparative Study of the Teachers Views about Selecting Appropriate Content for Social Studies Textbook of Primary School Third Grade, Iran
}

\author{
Mohammad Hosein Saket ${ }^{1} *$
}

\section{ABSTRACT}

Background: Textbook, which is one of the most important sources of the students learning in the educational systems also play an important role in the educational system of Iran. Purpose: This study was conducted to compare the views of male and female teachers and authors in the selection of appropriate content for Social Studies textbook of the primary school third grade. Method: the present study was conducted in the form of causal-comparative study using a questionnaire and the analysis of its items. Two groups of 107 male and female teachers teaching in public schools, private and Shahid schools of Tehran were selected using cluster sampling. Further, 6 authors of Social Studies book working in the Research and Educational Planning Organization of the Ministry of Education were selected based on their experience using targeted sampling method. Considering the nature of the questionnaire, 32 items developed by the researchers were completed by the research participants. The collected data were analyzed using nonparametric chi-square and Yates' correction for continuity tests in the software SPSS 19. Results: results of the study showed that there was no significant difference between the opinions of female and male teachers and authors. Findings: findings of the study showed that there was no significant gap in both scientific and ideological terms among the textbooks authors and teachers. Further, the sex of the teachers could not have any effect the difference in attitude toward the content of the books and this endorses the integrity of the education system.

Keywords: Comparison of the Teachers Views, Social Studies, Teachers' Views, Content Analysis, Primary School, Ministry Of Education

Education has long existed in human societies and human beings have considered education throughout history. Training program includes all the experiences, studies, discussions, group activities, individual and other actions that students do under the supervision and guidance of a teacher. Various aspects of student growth, talent, ability and their fitness for social life

\footnotetext{
${ }^{1}$ Conventional Master, University of Applied Science, Tehran, Iran.

*Responding Author

(C) 2016 I M Saket; licensee IJIP. This is an Open Access Research distributed under the terms of the Creative Commons Attribution License (http://creativecommons.org/licenses/by/2.0), which permits unrestricted use, distribution, and reproduction in any Medium, provided the original work is properly cited.
} 


\section{Comparative Study of the Teachers Views about Selecting Appropriate Content for Social Studies Textbook of Primary School Third Grade, Iran}

constitute the basis of school educational programs (Shariatmadari, 2007).

The major issues in the provision of education and training programs is to identify targets based on which the educational and training activities are designed and all those who somehow deal with education are quite acquainted with the educational goals. After explaining the educational goals in each educational course and setting new program, one has to act toward changing and selecting the appropriate content according to the purpose of the action.

In fact, the content is the core of any education program and has always been of interest to the experts. Thus, having appropriate content makes the accomplishment of the goal possible. Teachers, officials, planners and experts always arises question about the content of textbooks. For example, they ask "what course or subject should be taught?”, "How can it be taught?” and finally, "why should it be taught?” As it is known, the educational system in Iran has been based on textbooks and school is a part of the children world. They should learn the content of the book, so the content of the book is an important element of the curriculum. This research can be used by teachers, administrators and authors as well.

\section{METHODOLOGY}

The present study is conducted based on the comparative-descriptive method which is the comparison of the male and female teachers' view with the authors view about the textbook contents.

\section{Research Population and Sampling Method}

Population of the study included all the male and female teachers of the primary school in the 19 districts of Tehran, Iran in the Social Studies of the third grade and all the authors of the book working in the Research and Educational Planning Organization of the Ministry of Education. Considering the research nature, research participants were selected using cluster sampling method. For this purpose, three schools have been selected from each district and then the questionnaires were distributed among male and female teachers. After collecting the questionnaires and examining the required criterion, 107 questionnaires were included in the research. Further, 6 authors were selected based on targeted selection from among the authors working in the Research and Educational Planning Organization of the Ministry of Education based on the abilities considered by the researcher.

\section{Method of Data Collection}

The present study was conducted by performing the administrative procedures and direct visits with the research scholar of the selected schools. After coordination with school principals, questionnaires were distributed between male and female teachers and then were analyzed. In order to collect the data related to authors of social studies textbooks of the third grade. For required coordination, the researcher contacted the curriculum office of the Department of Social Studies Ministry of Education. 


\section{Comparative Study of the Teachers Views about Selecting Appropriate Content for Social Studies Textbook of Primary School Third Grade, Iran}

In order to extract the criteria for content selection, the opinions of the male and female teachers were examined via questionnaires and then were compared with the opinions of the authors. For this purpose, perfectly acceptable criteria were the answers with higher than the $65 \%$ approval. The acceptable criteria for answers were those approved over 50\% to 65\%, respectively, and finally criteria for weak responses were those with lower than 50\% approval, respectively. Then the common responses were analyzed and theoretical model was offered about the content of the courses.

\section{Research Instrument}

The instrument for data collection used in this study consists of a questionnaire designed as below:

\section{Questionnaire of the male and female teachers}

Questionnaire of the male and female teachers included 32 items based on a five-point Likert scale with five choices in response including very high, high, low, very low and ineffective. The items of the questionnaire fall into two general categories which are mostly related to content and small part of the questions is related to the learning experiences. The content questions include lesson content and some final questions at the end of the lesson.

\section{Questionnaire of the authors}

Questionnaire of the authors included 32 items based on a five-point Likert scale with five choices in response including very high, high, low, very low and ineffective. The items of the questionnaire fall into the content rather than the learning experiences.

Both the validity and reliability of the questionnaire were evaluated and its reliability using Cronbach's alpha coefficient was estimated as 0.78 and hence was not acceptable (Khosravi, 1997).

\section{Method of Data Analysis}

In order to analyze the data, descriptive and inferential statistics were applied. The research computing in the descriptive statistics included the determination of the frequency and percentage of female and male teachers' responses to the questionnaire and the analysis of the responses of teachers and authors of the textbooks on each questions of the questionnaire.

The Chi-square test was used for analysis of the inferential data in order to determine the relationship between male and female teachers as well as teachers with the authors of the book social studies for third grade in responding to the questions and determining the statistical significance of differences (Shivellson 1987).

Since the expected theoretical frequency of some choices was less than 5 , they were merged so the high and very high options were set in one group and very low, low and ineffective in another group. Data contingency table $2 \times 2$ was set with one degree of freedom. If the frequency of each group was less than 10 the modified Yates formula was used (Sharifi and Zand, 1991). 


\section{Comparative Study of the Teachers Views about Selecting Appropriate Content for Social Studies Textbook of Primary School Third Grade, Iran}

\section{RESULTS}

Table 1: Percentage of male and female teachers about appropriate content

\begin{tabular}{|c|c|c|}
\hline Item & Male \% & Female \% \\
\hline $\begin{array}{l}\text { Having a logical path and } \\
\text { sequence }\end{array}$ & $88 / 45$ & $89 / 08$ \\
\hline To understand the content & $76 / 92$ & $83 / 62$ \\
\hline $\begin{array}{l}\text { Understanding the rules and } \\
\text { regulations of society }\end{array}$ & $76 / 91$ & $76 / 36$ \\
\hline $\begin{array}{l}\text { The impact of the teacher } \\
\text { teaching methods on better } \\
\text { learning }\end{array}$ & $74 / 99$ & $72 / 92$ \\
\hline $\begin{array}{l}\text { Considering the purpose of } \\
\text { educational content }\end{array}$ & $71 / 15$ & $72 / 72$ \\
\hline Interest in learning & $67 / 30$ & $70 / 90$ \\
\hline $\begin{array}{lr}\text { Considering } & \text { the } \\
\text { environmental, cultural and } \\
\text { geographical variety }\end{array}$ & $67 / 29$ & $70 / 90$ \\
\hline $\begin{array}{l}\text { Considering the general } \\
\text { requirements of living }\end{array}$ & $63 / 45$ & $59 / 99$ \\
\hline $\begin{array}{l}\text { Strengthening the social } \\
\text { harmony and attention to ideas }\end{array}$ & $61 / 53$ & $56 / 36$ \\
\hline $\begin{array}{l}\text { Considering the need for } \\
\text { social and mental abilities }\end{array}$ & $57 / 68$ & $54 / 54$ \\
\hline $\begin{array}{l}\text { Developing the spirit of } \\
\text { cooperation }\end{array}$ & $53 / 85$ & $54 / 53$ \\
\hline $\begin{array}{l}\text { Considering the age } \\
\text { characteristics }\end{array}$ & $53 / 84$ & $52 / 71$ \\
\hline $\begin{array}{l}\text { Considering new concepts } \\
\text { and content not to approving } \\
\text { the acknowledge of the } \\
\text { previous books }\end{array}$ & 50 & $50 / 90$ \\
\hline
\end{tabular}




\section{Comparative Study of the Teachers Views about Selecting Appropriate Content for Social Studies Textbook of Primary School Third Grade, Iran}

Table 2: percentage of agreed opinions by the authors of textbooks

\begin{tabular}{|l|l|}
\hline Item & Percent \\
\hline Dominance of the culture and Islamic values & 100 \\
\hline Direct path and logical sequence of the content & $83 / 34$ \\
\hline $\begin{array}{l}\text { Environmental, cultural and geographical } \\
\text { diversity }\end{array}$ & $83 / 33$ \\
\hline To understand the content & $83 / 32$ \\
\hline Content based on educational goals & $66 / 67$ \\
\hline Being in accordance with the social rules & $66 / 66$ \\
\hline Considering the age characteristics & $66 / 16$ \\
\hline Strengthening the curiosity and research & 60 \\
\hline Accepting the status quo & 60 \\
\hline Interest in learning & 50 \\
\hline $\begin{array}{l}\text { The impact of the teacher teaching methods on } \\
\text { better learning }\end{array}$ & 50 \\
\hline Strengthening social adjustment & 50 \\
\hline Considering the mental abilities & 50 \\
\hline Association with higher core modules & 50 \\
\hline Considering the psychological needs & 50 \\
\hline considering the lower core modules & 50 \\
\hline
\end{tabular}

Table 3: Comparison of male and female teachers in frequency of opinions

\begin{tabular}{|l|l|l|l|}
\hline Choice & High & Low & Sum \\
\hline Male & 29 & 26 & 55 \\
\hline female & 32 & 20 & 52 \\
\hline Sum & 61 & 46 & 107 \\
\hline
\end{tabular}

Because the chi-square value at the error level of 0.05 with degrees of freedom equal to 1 was calculated as 0.846 and was smaller than the given the value in the table, the null hypothesis is accepted. So there is no significant difference between male and female teachers' opinions.

Table 4: Comparison of teachers and authors

\begin{tabular}{|l|l|l|l|}
\hline Choice & High & Low & Sum \\
\hline Male & 65 & 42 & 107 \\
\hline female & 2 & 4 & 6 \\
\hline Sum & 67 & 46 & 113 \\
\hline
\end{tabular}

Because the chi-square value at the error level of 0.05 with degrees of freedom equal to 1 was calculated as 0.815 and was smaller than the given the value in the table, the null hypothesis is accepted. So there is no significant difference between the opinions of teachers and those of authors. 


\section{Comparative Study of the Teachers Views about Selecting Appropriate Content for Social Studies Textbook of Primary School Third Grade, Iran}

\section{DISCUSSION}

This study aimed to examine the content of social studies textbooks of primary school in Iran by comparing the opinions of the male and female teachers and authors on the selection of appropriate content. In order to explain the research findings and providing a basis for presenting research results, an overview of the research background in the area of content analysis has to be provided. The ultimate goal was to improve the social studies program and conditions should be planned not only in the classroom but also in society at national and international levels for the development of intelligence, responsibility and leadership of the citizens. The content selection is an important task which needs further studies.

Tabari (1974) in a study entitled as "A comparative study of social understanding among elementary students in three groups of urban, rural and nomadic" , in a sample of 1,633 students in third grade and fifth grade, compared the social knowledge of the students considering the factors important in access to the media, teachers, social and culture class, language and their habitat.

The results showed that the level of social and political trust in urban students was more than in rural and nomadic students. Mirlohi in an article entitled as "In Search of the criteria for choosing the content" mentioned three critical criteria: 1 . Content is important for the present or future life. 2. Content must be important for the present and future employment situation. 3 . The content of the sample is an essential origin. Hassan Maleki in a study considered the main criteria for selection of content as credit and interest in learning, usefulness, ability to learn, flexibility, attention to structure, content knowledge, according to the preservation and promotion of cultural heritage and value system, establish and strengthen the scientific basis for continuing education, self-directing, communicating with daily life activities and create opportunities for learning multiple skills.

Another study entitled as the "Evaluation and comparison of elementary school social studies programs in Germany, the United States and Australia” have shown that the US primary school social studies programs were better than Australia and in Australia was better than Iran (Maleki, 1989). In addition, in the study as the "content analysis of the geography as a guide, based on Bloom's taxonomy of cognitive behavioral objectives" by Mohamadian, the role and importance of activities aimed at education were emphasized. In a study by Ali Akbar Khosravi about the criteria for selection of content and learning experiences in social studies on a sample of 240 junior teachers in Tehran, showed that the selection of content, the objectives, the proper balance between depth and course content, the creation of logical thinking, scientific spirit, interest in learning should be considered.

\section{LIMITATIONS OF THE STUDY}

Since the limitations of the research are highly important. The limitations have been divided into two parts, one for the researcher and the other one was out of control of the researcher. A - the 


\section{Comparative Study of the Teachers Views about Selecting Appropriate Content for Social Studies Textbook of Primary School Third Grade, Iran}

limitations of the research: (1) limiting the study to the third-grade social studies teacher (2) limiting the statistical population to nineteen regions in Tehran and (3) limiting the statistical population to practitioners and authors of textbooks of the third grade social studies book contents.

\section{B) Limitations out of the researcher control included}

1. The limitation of sampling; 2. No timely access to teachers due to their presence in the classroom; 3. Dispersion and differentiation of schools and districts which makes it difficult to have access to more schools at different times: 4 . the communication problems with schools of female students due to Islamic and school principals.

\section{Recommendations for future research}

The course Social Studies is a complement to other courses, so that it should be considered by other courses so that the interactive effects can be evaluated. It is required that the future studies use a wider range of teachers and authors of textbooks and teaching experience should be considered as an index in the selection of teachers as an important component.

\section{Acknowledgments}

The author appreciates all those who participated in the study and helped to facilitate the research process.

\section{Conflict of Interests}

The author declared no conflict of interests.

\section{REFERENCES}

Arizi Samani, H., and Abedi, A., Content analysis of primary school textbooks in terms of structure, motivation and development

Hakimzade, R ., Kiamanesh A., and Attaran M., Content Analysis of school textbooks based one the global problems and issues in the field of curriculum

Hosseininasab, D., and Dehghani, M., Content analysis of middle school social studies books on social skills and attitudes of teachers about the content of the above-mentioned books.

Khosravi, A., 1997, PhD thesis, A theoretical framework for the basic standards of choice of content and learning experiences in the social studies curriculum in first, second and third grade of secondary school in Iran, Islamic Azad University.

Maleki, H., 1995, organizing the content of the curriculum with an emphasis on social studies, Tehran, Swan publication.

Maleki, H., 1997, Curriculum (Practical Guide), printing, Tehran, school publications Sariatmadari, A., 1998. Society and education, Third Edition, Tehran, Amir Kabir Publications

Tabari, Sh., 1974, comparative assessment of students social knowledge in urban, rural and nomadic groups. 